Огляди літератури, оригінальні дослідження, погляд на проблему, ювілеї

УДК 616.34-008.87:616.366-002.2:616.379-008.64

DOI 10.11603/1811-2471.2018.v0.i2.8483

\title{
ДИСБІОЗ КИШЕЧНИКА У ХВОРИХ НА ЦУКРОВИЙ ДІАБЕТ 2 ТИПУ ТА ХРОНІЧНИЙ НЕКАЛЬКУЛЬОЗНИЙ ХОЛЕЦИСТИТ
}

\author{
๑є. С. Сірчак, С. М. Сідей, В. В. Вайс \\ ДВНЗ «Ужгородський національний університет»
}

РЕЗЮМЕ. Мета роботи - вивчити зміни кількісного і якісного складу мікрофлори товстої кишки у хворих на цукровий діабет (ЦД) 2 типу та хронічний некалькульзний холецистит (XНX).

Матеріал і методи. Під нашим спостереженням знаходилося 52 хворих, які перебували на стаціонарному лікуванні в гастроентерологічному та ендокринологічному відділеннях ЗОКЛ імені А. Новака м. Ужгород. Діагноз ЦП 2 типу встановлено згідно з рекомендаціями International Diabetes Federation (IDF, 2005 р.). Діагноз загострення XHX встановлювали згідно з клінічним протоколом МОЗ України та локальними протоколами. Усім обстеженим Хворим на ЦД 2 типута ХНХвиконано посів калу на дисбіоз. Ступінь дисбіозу кишечника оцінювали за класифікацією Куваєвої І. Б., Ладодо К. С. (1991 р.).

Результати. Основним клінічним проявом загострення XНХ у обстежених Хворих на ЦД II типу були больовий та диспепсичний синдроми. Ниючий біль локалізувався переважно в правому підребер'ї, із характерною іррадіацією у праве плече і праву лопатку. В обстежених хворих на ЦД 2 типу також визначали прояви біліарної та кишкової диспепсії (метеоризм, чергування проносів і запорів).

У всіх обстежених хворих на ЦД 2 типу та ХНХ за результатами мікробіологічного дослідження виявили зміни у кількісному і якісному складі мікрофлори товстої кишки. При цьому в обстежених хворих на ЦД 2 типу та XНХ встановили дисбіоз переважно III та II ступенів, а саме: дисбіоз III ступеня - у 53,9 \% хворих, II ступеня - у 36,5 \% хворих, і лише у 9,6 \% пацієнтів виявлено дисбіоз І ступеня. Встановлено, що диспепсичний синдром більш виражений і частіше виявляється у хворих на XНХ та ЦД 2 типу при дисбіозі III ступеня.

Висновки. 1. У хворих на ЦД 2 типу та ХНХ встановлено дисбіоз товстої кишки переважно ІІІ та II ступенів (У 53,9 \% та у 36,5 \% хворих відповідно). 2. Встановлено зв'язок між вираженістю проявів диспепсичного синдрому та дисбіозу переважно III ступеня у хворих на ЦД 2 типу та XНХ.

КлючОВІ СлОВА: цукровий діабет 2 типу; хронічний некалькульозний холецистит; дисбіоз кишечника.

Вступ. Цукровий діабет (ЦД) - особливе захворювання, на фоні якого в останні роки відзначається зростання поліморбідних патологій. При ЦД порушуються всі види обміну речовин, у результаті чого різною мірою уражаються всі органи і системи організму, в тому числі й система органів травлення (СОТ) (шлунок, кишечник, печінка, підшлункова залоза, жовчовидільна система). Важливу роль у розвитку цих уражень відіграють не тільки метаболічні розлади, а й виникнення діабетичної автономної нейропатії, імунологічних порушень та інших наслідків ЦД [1].

У 75 \% випадків ЦД супроводжується ураженням СОТ. Це, як власне гастроінтестинальні зміни (дисфункція стравоходу, гастропатія, сповільнення евакуаторної функції шлунка, діабетична діарея, запори, нетримання калу), в основі яких лежить діабетична нейропатія, так і стани, пов'язані з гормонально-метаболічними порушеннями [2].

Порушення жовчоутворювальної і жовчовидільної функцій печінки, гіпотонія і гіпокінезія жовчного міхура, зниження концентраційної і евакуаторної його функцій сприяє збільшенню його об'єму і холестазу. Холестаз спостерігається більш ніж у половини осіб з ЦД, особливо при наявності ожиріння, i супроводжується розвитком жовчнокам'яної хвороби, дискінезії жовчовивідних шляхів, хронічного холециститу (XX) [3].
Порушення моторної і секреторної функцій шлунка та кишечника з міграцією бактеріальної флори з проксимальних відділів кишки $є$ несприятливим фактором, що створює умови для розвитку патогенної мікрофлори (дисбактеріоз) і сприяє формуванню хронічного коліту. Сьогодні доведено взаємозв'язок мікробіоти кишечника і захворювань печінки, тому не можна лікувати пацієнтів зі стеатозом, метаболічним синдромом без корекції порушень кишкової мікрофлори [2, 3]. Отже, у хворих на ЦД та XX також доцільним $\epsilon$ дослідження кількісного і якісного складу мікрофлори товстої кишки.

Мета роботи - вивчити зміни кількісного і якісного складу мікрофлори товстої кишки у хворих на ЦД 2 типу та хронічний некалькульзний холецистит (XHX).

Матеріал і методи дослідження. Під нашим спостереженням перебували 52 хворих, які отримували стаціонарне лікування в гастроентерологічному та ендокринологічному відділеннях ЗОКЛ імені А. Новака, м. Ужгород. Усі дослідження були проведені за згодою пацієнтів, а їх методика відповідала Гельсінській декларації 1975 р. та її перегляду 1983 р. Хворі були віком від 28 до 69 років, середній вік складав $(52,3 \pm 7,6)$ років; чоловіків було 20 (38,5\%), жінок - 32 (61,5\%). У контрольну групу ввійшли 20 практично здорових осіб віком від 22 
Огляди літератури, оригінальні дослідження, погляд на проблему, ювілеї

до 62 років, середній вік складав $(45,2 \pm 8,2)$ років. Чоловіків було 8 (40,0\%), жінок - 12 (60,0\%).

Усім обстеженим хворим виконано загальноклінічні дослідження. Діагноз ЦП 2 типу встановлювали згідно з рекомендаціями International Diabetes Federation (IDF, 2005 р.). Визначення рівня глюкози у сироватці крові натще і через 2 години після прийому їжі проводили глюкозооксидантним методом. Ступінь тяжкості ЦД 2 типу оцінювали за рівнем глікозильованого гемоглобіну (HbA1c, \%) (хромогенний аналіз, апарат Sysmex 560, Японія) із використанням реактивів фірми Siemens. Діагноз загострення XHX встановлювали згідно з клінічним протоколом МОЗ України та локальними протоколами, з урахуванням скарг, анамнестичних, лабораторних та інструментальних (ультразвукове дослідження органів черевної порожнини, апарат Philips HDI - 1500, США; дуоденальне зондування) методів дослідження.

Усім обстеженим Хворим на ЦД 2 типу та XНХ виконано посів калу на дисбіоз. При цьому проводили кількісний облік мікроорганізмів, які виросли на поживному середовищі агар, Сабуро, Ендо та 5 \% кров'яному агарі з перерахунком на 1 г фекалій. На чашці з 5 \% кров'яним агаром відмічали наявність гемолітичних форм як кишкової, так і кокової мікрофлори, відсоток їх від загальної кількості колоній, які виросли, співвідношення кишкової та кокової мікрофлори. Наявність біфідобактерій визначали за характером росту на середовищі Блаурока та мікроскопії мазків, пофар- бованих за Грамом. Кількість біфідобактерій та лактобацил в одному грамі фекалій визначали за граничним розведенням, при якому спостерігався їх ріст. Ступінь дисбіозу кишечника оцінювали за класифікацією Куваєвої І. Б., Ладодо К. С. (1991р.).

Аналіз і обробку результатів обстеження хворих здійснювали за допомогою комп'ютерної програми STATISTICA (StatSoft Inc, USA) з використанням параметричних та непараметричних методів оцінки отриманих результатів.

Наукове дослідження $є$ фрагментом держбюджетної теми кафедри хірургічних хвороб та пропедевтики внутрішніх хвороб медичного факультету ДВНЗ «УжНУ» № 851 «Механізми формування ускладнень при захворюваннях печінки та підшлункової залози, методи їх лікування та профілактики», номер державної реєстрації: $0115 \cup 001103$.

Результати й обговорення. Основним клінічним проявом загострення XHX у обстежених хворих на ЦД 2 типу були больовий та диспепсичний синдроми. Біль ниючого характеру локалізувався переважно в правому підребер'ї, із характерною іррадіацією у праве плече і праву лопатку. Больові відчуття виникали або посилювались після вживання жирної або смаженої їжі. У обстежених хворих на ЦД 2 типу також визначали прояви біліарної диспепсії, що характеризувались нудотою, відрижкою гірким, гірким присмаком у роті та кишковою диспепсією (метеоризм, чергування проносів і запорів). Результати наведені у таблиці 1.

Таблиця 1. Клінічні прояви ХНХ у хворих на ЦД 2 типу

\begin{tabular}{|l|c|c|}
\hline \multirow{2}{*}{ Клінічні синдроми } & \multicolumn{2}{|c|}{ Обстежені хворі на ХНХ та ЦД 2 типу (n=52) } \\
\cline { 2 - 3 } & абсолютна кількість & 100,0 \\
\hline Больовий & 52 & 61,5 \\
\hline \multicolumn{2}{|c|}{ Нудота } & Диспепсичний \\
\hline Блювання & 32 & 28,8 \\
\hline Відрижка гірким & 15 & 78,8 \\
\hline Гіркота у роті & 41 & 71,2 \\
\hline Метеоризм & 37 & 55,8 \\
\hline $\begin{array}{l}\text { Порушення акту дефекації (проноси, } \\
\text { що чергуються з запорами) }\end{array}$ & 29 & 80,8 \\
\hline
\end{tabular}

У всіх обстежених хворих на ЦД 2 типу та XНХ за результатами мікробіологічного дослідження виявили зміни у кількісному і якісному складі мікрофлори товстої кишки. При цьому у обстежених хворих на ЦД 2 типу та ХНХ встановили дисбіоз переважно III та II ступенів, а саме: дисбіоз III ступеня -у 53,9 \% хворих, II ступеня -у 36,5 \% хворих, і лише у 9,6\% пацієнтів встановлено дисбіоз І ступеня.

Дисбіотичні зміни у обстежених нами хворих на ЦД 2 типу та XHX проявлялись зменшенням за- гальної кількості біфідо- та лактобактерій, що паралельно супроводжувалось збільшенням кількості патогенних та умовно-патогенних штамів мікроорганізмів. Результати представлені у таблиці 2.

Після аналізу скарг та отриманих результатів мікробіологічного дослідження калу встановлено, що диспепсичний синдром (прояви як біліарної, так і кишкової диспепсії) більш виражений і частіше виявляється у хворих на XНХ та ЦД 2 типу при дисбіозі III ступеня. 
Огляди літератури, оригінальні дослідження, погляд на проблему, ювілеї

Таблиця 2. Зміна кількісного та якісного складу мікрофлори товстої кишки у хворих на ЦД II типу та ХHX

\begin{tabular}{|c|c|c|c|c|}
\hline \multirow{3}{*}{ Показник } & \multicolumn{4}{|c|}{ Обстежені } \\
\hline & \multicolumn{2}{|c|}{$\begin{array}{l}\text { контрольна група } \\
(n=20)\end{array}$} & \multicolumn{2}{|c|}{$\begin{array}{c}\text { хворі на ЦД ІІ типу та XНХ } \\
(\mathrm{n}=52)\end{array}$} \\
\hline & частота, \% & $\lg \mathrm{KУO} / г$ & частота, \% & $\lg \mathrm{KУO} / г$ \\
\hline Bifidobacterium & 100,0 & $8,66 \pm 0,21$ & 78,8 & $5,89 \pm 0,17$ ** \\
\hline Lactobacillus & 100,0 & $6,92 \pm 0,18$ & 80,8 & $5,01 \pm 0,28$ * \\
\hline Escherichia & 100,0 & $7,88 \pm 0,15$ & 75,0 * & $6,02 \pm 0,12$ * \\
\hline Enterococcus & 95,0 & $7,41 \pm 0,26$ & $42,3^{*}$ & $5,99 \pm 0,14$ * \\
\hline Enterobacter & 25,0 & $1,18 \pm 0,12$ & $76,9 * *$ & $3,44 \pm 0,15$ ** \\
\hline Citrobacter & 50,0 & $1,52 \pm 0,08$ & $19,2 * *$ & $2,76 \pm 0,23$ \\
\hline Staphylococcus & 35,0 & $3,25 \pm 0,20$ & $67,3 *$ & $4,86 \pm 0,20$ * \\
\hline Klebsiella & 25,0 & $1,08 \pm 0,15$ & $51,9 *$ & $3,74 \pm 0,18$ ** \\
\hline Clostridium & 15,0 & $4,26 \pm 0,20$ & 48,0 ** & $5,73 \pm 0,25$ \\
\hline Proteus & 10,0 & $0,34 \pm 0,11$ & $38,5^{*}$ & $2,08 \pm 0,17$ ** \\
\hline Candida & 10,0 & $3,12 \pm 0,09$ & 19,2 & $4,69 \pm 0,13$ * \\
\hline
\end{tabular}

Примітка. Відмінності між показниками контрольної групи та обстеженими хворими на ЦД 2 типу та XНХ достовірні: * - p<0,05; $* *-p<0,01$.

Отже, вивчення кишкової мікрофлори у хворих на XНХ та ЦД 2 типу є необхідним елементом для проведення ефективного лікування, що має бути спрямовано на зменшення клінічної симптоматики та покращення показників якості життя у даних пацієнтів.

Висновки. 1. У хворих на ЦД 2 типу та ХНХ встановлено дисбіоз товстої кишки переважно III та II ступенів (у 53,9 \% та у 36,5 \% хворих відповідно).
2. Встановлено зв'язок між вираженістю проявів диспепсичного синдрому та дисбіозу переважно III ступеня у хворих на ЦД 2 типу та XНX.

Перспективи подальших досліджень. Подальше вивчення особливостей кількісного та якісного складу мікрофлори товстої кишки у хворих на ЦД 2 типу та XНХ необхідне для розробки ефективних методів їх лікування та профілактики.

\section{ЛІТЕРАТУРА}

1. Фадєєнко Г. Д. Ураження гастродуоденальної ділянки у хворих на цукровий діабет: клініко-популяційні аспекти / Г. Д. Фадєєнко, В. А. Чернишов // Ліки України. - 2011. - № 7 (153). - С. 48-50.

2. Степанов Ю. М. Новые возможности терапии сахарного диабета и сопутствующих заболеваний: междисциплинарные аспекты [Электронный ресурс] / Ю. М. Степанов. - По итогам научно-практической конференции «Сахарный диабет как интегральная проб-

\section{REFERENCES}

1. Fadieienko, H.D., \& Chernyshov, V.A. (2011). Urazhennia hastroduodenalnoi dilianky u khvorykh na tsukrovyi diabet: kliniko-populyatsiini aspekty [Defeat of the gastroduodenal region in patients with diabetes mellitus: clinical and population aspects]. Liky Ukrainy Medicines of Ukraine, 7 (153), 48-50 [in Ukrainian].

2. Stepanov, Yu.M. Novyye vozmozhnosti terapii sakharnogo diabeta i soputstvuyushchikh zabolevaniy: mezhdistsiplinarnyye aspekty [New possibilities of therapy of diabetes mellitus and concomitant diseases: interdisciplinary aspects]. Po itogam nauchno-prakticheskoy konferentsii "Sakharnyy diabet kak integralnaya problema лема внутренней медицины». - Режим доступа: http:// www.umj.com.ua/article/89706/novye-vozmozhnostiterapii-saxarnogo-diabeta-i-soputstvuyushhix-zabolevanijmezhdisciplinarnye-aspekty

3. Особенности поражения органов пищеварения при сахарном диабете / [Л. А. Песоцкая, А. А. Лукьяненко, Е. А. Кулькина и др.] // Клінічна та експериментальна медицина. - 2013. - Вип. 1, Т. 2 (99). - С. 149-153.

vnutrenneymeditsiny"-Following the Results of the Scientific and Practical Conference "Diabetes mellitus as an integral problem of internal medicine". - Retrieved from: http:// www.umj.com.ua/article/89706/novye-vozmozhnostiterapii-saxarnogo-diabeta-i-soputstvuyushhix-zabolevanij-mezhdisciparnarnye-aspekty [in Russian].

3. Pesotskaya, L.A., Lukyanenko, A.A., \& Kulkina, E.A. (2013). Osobennosti porazheniya organov pishchevareniya pri sakharnom diabete [Features of the defeat of the digestive system in diabetes mellitus]. Klinichna ta eksperymentalna medytsyna - Clinical and Experimental Medicine, 1, 2 (99), 149-153 [in Russian]. 


\title{
Огляди літератури, оригінальні дослідження, погляд на проблему, ювілеї ДИСБИОЗ КИШЕЧНИКА У БОЛЬНЫХ САХАРНЫМ ДИАБЕТОМ ІІ ТИПА И ХРОНИЧЕСКИМ НЕКАЛЬКУЛЕЗНЫМ ХОЛЕЦИСТИТОМ
}

\author{
ОЕ. С. Сирчак, С. М. Сидей, В. В. Вайс
}

\author{
ГВУз «Ужгородский национальный университет»
}

РЕЗЮМЕ. Цель работы - изучить изменения количественного и качественного состава микрофлоры толстой кишки у больных сахарным диабетом (СД) 2 типа и хроническим некалькулезным холециститом (ХHX).

Материал и методы. Под нашим наблюдением находилось 52 больных, получавших стационарное лечение в гастроэнтерологическом и эндокринологическом отделениях ЗОКБ имени А. Новака г. Ужгород. Диагноз СД 2 типа установлен в соответствии с рекомендациями International Diabetes Federation (IDF, 2005). Диагно3 обострения XНХ устанавливали согласно клиническому протоколу МЗ Украины и локальным протоколам. Всем обследованным больным СД 2 типа и XНХ выполнен посев кала на дисбактериоз. Степень дисбиоза кишечника оценивали по классификации Куваева И. Б., Ладодо К. С. (1991 г.).

Результаты. Основным клиническим проявлением обострения ХНХ у обследованных больных СД 2 типа были болевой и диспепсический синдромы. Боль ноющего характера локализовалась преимущественно в правом подреберье, с характерной иррадиацией в правое плечо и правую лопатку. У обследованных больных СД 2 типа также определяли проявления билиарной и кишечной диспепсии (метеоризм, чередование поносов и запоров).

У всех обследованных больных СД 2 типа и XHX по результатам микробиологического исследования выявили изменения количественного и качественного состава микрофлоры толстой кишки. При этом у обследованных больных СД 2 типа и XНX установили дисбиоз преимущественно III и II степеней, а именно: дисбиоз III степени - у 53,9 \% больных, II степени - у 36,5 \% больных, и только у 9,6 \% пациентов выявлен дисбиоз I степени. При этом диспепсический синдром более выражен и чаще обнаруживается у больных ХНХ и СД2 типа при дисбиозе III степени.

Выводы. 1. У больных СД 2 типа и ХНХ установлен дисбиоз толстой кишки преимущественно III и II степеней (у 53,9 \% и 36,5 \% больных соответственно). 2. Установлена взаимосвязь между выраженностью проявлений диспепсического синдрома и дисбиозом преимущественно III степени у больных СД II типа и XHX.

КЛЮчЕВЫЕ СЛОВА: сахарный диабет II типа; хронический некалькулезный холецистит; дисбиоз кишечника.

\section{LARGE INTESTINE DYSBIOSIS IN PATIENTS WITH COMBINATION OF DIABETES MELLITUS TYPE 2 AND CHRONIC NONCALCULOUS CHOLECISTITIS}

\author{
๑Ye. S. Sirchak, S. M. Sidey, V. V. Vajs \\ Uzhhorod National University
}

SUMMARY. The aim of the study - to learn the changes in the quantitative and qualitative composition of the large intestine microflora in patients with diabetes mellitus (DM) type 2 and chronic noncalculous cholecystitis (CAC).

Material and Methods. 52 patients who were treated in the Gastroenterological and Endocrinology Departments of the Transcarpathian Regional Hospital named after A. Novak in Uzhhorod were involved in the study. DM type 2 diagnosis was based on the recommendations of the International Diabetes Federation (IDF, 2005). The exacerbation of the CNC diagnosis was based in accordance with the clinical protocol of the Ministry of Health of Ukraine and local protocols. The feces for dysbiosis were examined in patients with DM type 2 and CNC. The degree of intestinal dysbiosis was evaluated according to the classification of Kuvayeva I. B., Ladodo K. S. (1991).

Results. The main clinical manifestation of the exacerbation of CNC in examined patients with DM type 2 was pain and dyspepsia syndromes. The nagging pain was localized mainly in the right hypochondria region with a characteristic irradiation to the right shoulder and right shoulder blade. The manifestations of biliary dyspepsia and intestinal dyspepsia (flatulence, alternating diarrhea and constipation) were examined in patients with DM type 2. Changes in the quantitative and qualitative composition of the large intestine microflora were observed in all examined patients with DM type 2 and CNC according to the results of microbiological study. At the same time, dysbiosis, mainly III and II degrees were found in patients with combination of DM type 2 and CNC, namely - III degree dysbiosis in $53.9 \%$ of patients, II degree - in $36.5 \%$ of patients and only $9.6 \%$ of patients had I degree dysbiosis. It has been established that dyspeptic syndrome is more pronounced and more commonly found in patients with combination of CAC and DM type 2 with III degree dysbiosis.

Conclusions. 1. The large intestine dysbiosis, mainly III and II degrees (in $53.9 \%$ and $36.5 \%$ of patients respectively) was observed in patients with DM type 2 and CNC.2. The connection between the severity of manifestations of dyspeptic syndrome and dysbiosis, mainly of the III degree were observed in patients with DM II type and CNC.

KEY WORDS: diabetes mellitus type 2; chronic noncalculous cholecystitis; intestinal dysbiosis. 